Original research

\title{
Vigorous and moderate physical activity among overweight and obese adults in Malaysia: Sociodemographic correlates
}

\author{
Yong Kang Cheah ${ }^{\mathrm{a}, *}$, Mohd Azahadi ${ }^{\mathrm{b}}$, Siew Nooi Phang ${ }^{\mathrm{c}}$, Noor Hazilah Abd Manaf ${ }^{\mathrm{d}}$ \\ ${ }^{a}$ School of Economics, Finance and Banking, College of Business, Universiti Utara Malaysia, UUM Sintok, Kedah Darul Aman, 06010, Malaysia \\ ${ }^{\mathrm{b}}$ Research Planning and Policy Division, National Institute of Health, No. 1, Jln Setia Murni U13/52, Seksyen U13, 40170, Shah Alam, Selangor, Malaysia \\ ${ }^{\mathrm{c}}$ School of Government, College of Law, Government and International Studies, Universiti Utara Malaysia, 06010, UUM Sintok, Kedah Darul Aman, Malaysia \\ ${ }^{\mathrm{d}}$ Department of Business Administration, Faculty of Economics and Management Sciences, International Islamic University Malaysia, 50728, Kuala Lumpur, Malaysia
}

\section{A R T I C L E I N F O}

\section{Keywords:}

Exercise

Income

Obesity

Overweight

Physical activity

\begin{abstract}
A B S T R A C T
Background: This study examines the effects of sociodemographic factors on participation in vigorous and moderate physical activity and how they vary across bodyweight group (underweight, normal, overweight, obese I, obese II).

Methods: This study uses a nationally representative data with a sample of 10141 respondents. Bivariate and multivariate analyses are stratified by bodyweight group. The intensity of physical activity is measured using metabolic equivalent (MET). Vigorous physical activity has $>6 \mathrm{MET}$, while moderate physical activity has $\leq 6$ MET.

Results: Several important findings are noteworthy. First, age has a positive impact on moderate physical activity among obese I individuals but a negative impact on moderate physical activity among obese II individuals. Second, education is significant in determining participation in all intensity levels of physical activity among obese I individuals. Third, higher income obese II individuals spend less time in vigorous physical activity than their lower income counterparts. However, higher income overweight and obese I individuals spend less time in moderate physical activity compared with those who have lower income. Fourth, overweight, obese I and obese II males spend more time in vigorous and total physical activity than their female counterparts, but they allocate less time for moderate physical activity.

Conclusions: It appears that sociodemographic factors play an important role in determining participation in vigorous and moderate physical activity among overweight and obese adults. We conclude by discussing implications for policies directed towards promoting physically active lifestyle among overweight and obese adults who are unlikely to spend time in physical activity.
\end{abstract}

\section{Introduction}

In today's rapidly urbanising society, overweight and obesity have become a serious public health concern across the globe. The prevalence of overweight and obesity has increased tremendously since 1975. In 2016, approximately 1250 million adults were overweight and 650 million were obese (World Health Organization, 2018a). This was equivalent to $39 \%$ and $13 \%$ of total adult population worldwide, respectively (World Health Organization, 2018a). Overweight and obesity are responsible for more deaths than underweight as they are usually related to various chronic diseases, such as heart disease, stroke, diabetes and cancers. Overweight and obesity and their related diseases in Malaysia are also a growing national concern. As pointed out by Lum (2018), Malaysia has the highest number of overweight and obese people in Asia. In 2015, about 30\% and $17.7 \%$ of adults in Malaysia were overweight and obese, respectively (Institute for Public Health, 2015). In the same year, the prevalence of hypercholesterolemia, hypertension and diabetes were $47.7 \%, 30.3 \%$ and 17.5\%, respectively (Institute for Public Health, 2015).

One of the main contributing factors to overweight and obesity is physical inactivity (World Health Organization, 2018b). Being physically active helps to reduce bodyfat, thus preventing numerous chronic diseases. This indicates that if overweight and obese people could devote more time to physical activity, their health would improve substantially. In spite of the importance of physical activity, people seldom spend sufficient time carrying it out. According to the World Health Organization, individuals should spend at least 150 or $75 \mathrm{~min}$ per week (min/wk) in moderate or

\footnotetext{
* Corresponding author. School of Economics, Finance and Banking, College of Business, Universiti Utara Malaysia, 06010, UUM Sintok, Kedah Darul Aman, Malaysia.

E-mail addresses: cheahykang@gmail.com (Y.K. Cheah), drazahadi@moh.gov.my (M. Azahadi), siewnooi@uum.edu.my (S.N. Phang), hazilah@iium.edu.my (N.H. Abd Manaf).
} 
vigorous physical activity, respectively, in order to stay physically active (World Health Organization, 2018b). However, more than 25\% of adults do not meet this requirement (World Health Organization, 2018b). The prevalence of physical inactivity in Malaysia is also alarming. As the report shows, in 2015, about $33.5 \%$ of adults in Malaysia did not live a physically active lifestyle (Institute for Public Health, 2015). Being physically inactive during leisure time, living a hectic lifestyle, having less physically demanding jobs and frequent use of transportation are among the common reasons for this phenomena.

The important role of physical activity in improving health has motivated researchers from various countries to study factors affecting participation in physical activity. Previous studies have often focused on developed countries given their wide availability of data, especially in the United States (US) (Meltzer and Jena, 2010; Humphreys and Ruseski, 2011; Brown and Roberts, 2011) and European countries (Farrell and Shields, 2002; Downward and Rasciute, 2010; Eberth and Smith, 2010; Ruseski et al., 2011). Rarely, if any, have past studies paid attention to Malaysia, a rapid-growing developing country with a high obesity rate. Chan et al. (2017) are among a few researchers in Malaysia who have examined the association between physical activity and overweight, and obesity. Their findings suggest that low level of physical activity is associated with an increased likelihood of being overweight and obese. While Chan et al. (2017) have provided important findings on the relationship between physical activity, overweight and obesity, they have not investigated the factors that affect participation in physical activity among overweight and obese adults. The physical activity pattern among overweight and obese adults is still poorly understood. Since overweight and obese individuals are at risk to various diseases, it is essential to understand the factors that can alter their physical activity behaviour.

The present study differs in several ways from the study of Chan et al. (2017). Firstly, this study makes a unique contribution by examining how the effects of sociodemographic factors on physical activity vary across bodyweight group. In particular, it offers a comprehensive understanding between different types of overweight and obese people and the time each type spends on physical activity. Our analyses are stratified by bodyweight group (overweight, obese I, obese II), and this stratification is of importance as it can provide insightful information on physical activity behaviour among overweight and obese people, which can be useful for the development of intervention measures.

Another significant feature of this study is that it provides an in-depth examination of the intensity of physical activity. To date, sociodemographic factors associated with vigorous and moderate physical activity have not been widely studied. People who spend more time in vigorous physical activity do not necessarily spend more time in moderate physical activity as well. In other words, the factors that are correlated with vigorous physical activity may be different from the factors associated with moderate physical activity (Meltzer and Jena, 2010). Hence, it would be beneficial to understand the time allocation decisions of these two intensity levels of physical activity. Without putting efforts into examining the intensity of physical activity, inaccurate conclusions may be derived, resulting in inappropriate policy decisions.

\section{Methods}

\subsection{Data}

Secondary analysis of the National Health and Morbidity Survey 2011 (NHMS 2011) was used. The NHMS 2011 was among a few nationally representative surveys conducted by the Ministry of Health Malaysia. The NHMS 2011 was not the most recent survey, but it had a large sample size $(\mathrm{n}=10141)$ and detailed information on individuals' physical activity and sociodemographic profiles. Although secondary analysis of an existing survey was conducted instead of primary analysis, there was a seemingly a large sample size and high quality data. The sampling method used in the survey was a two-stage stratified sampling designed for the Malaysian National Population and Housing Census. Firstly, a total of 794 Enumeration Blocks (EBs) were selected, and each EB comprised a total of 500-600 populations. Secondly, twelve living quarters (LQs) were randomly selected from each EB and members of households in the selected LQs were surveyed. Inclusion criteria were people residing in all the states in Malaysia, while exclusion criteria were non-Malaysians and institutionalised individuals, such as those staying in hospitals, hostels and hotels.

During the survey, separate questionnaires were used for face-toface interview and self-administration. The main language used in these questionnaires was Malay, i.e. the national language of Malaysia. Nevertheless, it was translated to English, Mandarin and Tamil to facilitate a better understanding, especially given that the targeted respondents were from various ethnic backgrounds. Additionally, the respondents' weight and height were measured during the survey in order to calculate their body mass index (BMI). BMI was used to determine whether the respondents underweight (BMI $\leq 18.49$ ), normal (18.50 $\leq$ BMI $\leq 22.99)$, overweight $(23.00 \leq \mathrm{BMI} \leq 24.99)$, obese I $(25$ $\leq$ BMI $\leq 29.99$ ) and obese II (BMI $\geq 30$ ). These bodyweight categories were determined based on the Asian guideline set by the World Health Organization (Tan et al., 2012). In an effort to ensure that the survey was of sufficiently high quality, training courses were made mandatory for all the interviewers. The training courses covered mock interviews and pilot studies. Each and every respondent was required to fill and sign the consent form or provide thumb print. The NHMS 2011 was described in great detail elsewhere (Institute for Public Health, 2011).

\subsection{Dependent variables}

Three dependent variables are used in the present study: 1) time spent in moderate physical activity; 2) time spent in vigorous physical activity; 3) time spent in total physical activity. The units are in $\mathrm{min} / \mathrm{wk}$ regardless of whether physical activity occurs in smaller sessions spread over the week or only one or two large periods of time. The sum of moderate and vigorous physical activity equals to total physical activity. The information on physical activity is obtained by asking the respondents several questions: 1) 'Over the last seven days, how many days did you participate in physical activity for at least $10 \mathrm{~min}$ per session?' 2) 'On the days you participated in physical activity, how many minutes did you spend?' Because of data limitation, we are unable to analyse the specific exercises that are under consideration for physical activity variable.

The intensity of physical activity is determined based on metabolic equivalent (MET). MET is the ratio of metabolic rate during exercise to metabolic rate when sitting quietly (Ainsworth et al., 1993). Hence, MET of one is when a person sits quietly. If a person uses four times the energy of sitting quietly to perform physical activity, MET is four. In general, vigorous physical activity has $>6 \mathrm{MET}$, while moderate physical activity has $\leq 6$ MET. Details and examples of vigorous and moderate physical activity have been described by Ainsworth et al. (1993).

\subsection{Independent variables}

BMI is used as one of the independent variables. The sociodemographic variables are selected based on the findings of previous studies (Farrell and Shields, 2002; Meltzer and Jena, 2010; Downward and Rasciute, 2010; Eberth and Smith, 2010; Ruseski et al., 2011; Humphreys and Ruseski, 2011; Brown and Roberts, 2011; Cheah and Poh, 2014; Cheah et al., 2017). Age is formatted as a categorical variable with five categories: $\leq 29,30-39,40-49,50-59$ and $\geq 60$. In addition, the respondents are asked to report their highest education level and monthly individual income [Ringgit Malaysia (RM)]. Education variable has three categories (primary, secondary and tertiary), while income variable has five categories ( $\leq 999,1000-1999,2000-2999,3000-3999$ and $\geq 4000$ ).

The respondents' gender is recorded and used as one of the independent variables. The respondents are also asked to report their ethnic backgrounds. Based on their responses, four categories are 
Table 1

Summary statistics of the independent variables, by bodyweight. Source: NHMS 2011

\begin{tabular}{|c|c|c|c|c|c|}
\hline Variables & Underweight & Normal & Overweight & Obese I & Obese II \\
\hline \multicolumn{6}{|l|}{ Age (years) } \\
\hline 29 & 354 (54.88) & $1058(38.46)$ & 358 (23.37) & $539(18.60)$ & $334(21.80)$ \\
\hline $30-39$ & $104(16.12)$ & 551 (20.03) & $342(22.32)$ & 636 (21.95) & 347 (22.65) \\
\hline $40-49$ & $60(9.30)$ & $460(16.72)$ & $342(22.32)$ & $726(25.05)$ & 364 (23.76) \\
\hline $50-59$ & 47 (7.29) & 367 (13.34) & $281(18.34)$ & $624(21.53)$ & $330(21.54)$ \\
\hline$\geq 60$ & $80(12.40)$ & 315 (11.45) & 209 (13.64) & $373(12.87)$ & $157(10.25)$ \\
\hline \multicolumn{6}{|l|}{ Education } \\
\hline Primary & $134(20.78)$ & 687 (24.97) & $429(28.00)$ & $748(25.81)$ & $408(26.63)$ \\
\hline Secondary & 332 (51.47) & 1251 (45.47) & $686(44.78)$ & 1423 (49.10) & 779 (50.85) \\
\hline Tertiary & $179(27.75)$ & $813(29.55)$ & $417(27.22)$ & 727 (25.09) & $345(22.52)$ \\
\hline \multicolumn{6}{|l|}{ Income (RM) } \\
\hline$\leq 999$ & $334(51.78)$ & $1273(46.27)$ & $652(42.56)$ & 1151 (39.72) & $678(44.26)$ \\
\hline 1000-1999 & $184(28.53)$ & $753(27.37)$ & $378(24.67)$ & 695 (23.98) & 378 (24.67) \\
\hline 2000-2999 & $76(11.78)$ & $329(11.96)$ & 241 (15.73) & 444 (15.32) & $208(13.58)$ \\
\hline 3000-3999 & $34(5.27)$ & $201(7.31)$ & $106(6.92)$ & $281(9.70)$ & $118(7.70)$ \\
\hline$\geq 4000$ & $17(2.64)$ & 195 (7.09) & $155(10.12)$ & $327(11.28)$ & 150 (9.79) \\
\hline \multicolumn{6}{|l|}{ Gender } \\
\hline Male & 307 (47.60) & $1262(45.87)$ & 745 (48.63) & 1479 (51.04) & 599 (39.10) \\
\hline Female & $338(52.40)$ & $1489(54.13)$ & 787 (51.37) & 1419 (48.96) & $933(60.90)$ \\
\hline \multicolumn{6}{|l|}{ Ethnicity } \\
\hline Malay & 333 (51.63) & $1266(46.02)$ & 751 (49.02) & $1573(54.28)$ & 943 (61.55) \\
\hline Chinese & $174(26.98)$ & $820(29.81)$ & 441 (28.79) & $669(23.08)$ & $233(15.21)$ \\
\hline Indian & 63 (9.77) & $252(9.16)$ & $147(9.60)$ & $300(10.35)$ & $194(12.66)$ \\
\hline Others & 75 (11.63) & $413(15.01)$ & $193(12.60)$ & $356(12.28)$ & $162(10.57)$ \\
\hline \multicolumn{6}{|l|}{ Marital status } \\
\hline Single & 335 (51.94) & $938(34.10)$ & $329(21.48)$ & $461(15.91)$ & 281 (18.34) \\
\hline Married & $268(41.55)$ & $1633(59.36)$ & 1098 (71.67) & $2233(77.05)$ & $1123(73.30)$ \\
\hline Divorce & $42(6.51)$ & $180(6.54)$ & $105(6.85)$ & $204(7.04)$ & $128(8.36)$ \\
\hline \multicolumn{6}{|l|}{ Family size } \\
\hline Small & 344 (53.33) & $1557(56.60)$ & 869 (56.72) & $1609(55.52)$ & 853 (55.68) \\
\hline Medium & $237(36.74)$ & 968 (35.19) & $558(36.42)$ & 1072 (36.99) & $566(36.95)$ \\
\hline Large & $64(9.92)$ & $226(8.22)$ & $105(6.85)$ & $217(7.49)$ & $113(7.38)$ \\
\hline \multicolumn{6}{|l|}{ Employment } \\
\hline Employed & $403(62.48)$ & 1807 (65.69) & $1019(66.51)$ & $1940(66.94)$ & $954(62.27)$ \\
\hline Unemployed & $242(37.52)$ & $944(34.31)$ & $513(33.49)$ & $958(33.06)$ & 578 (37.73) \\
\hline \multicolumn{6}{|l|}{ Insurance } \\
\hline Insured & 304 (47.13) & $1397(50.78)$ & $828(54.05)$ & $1578(54.45)$ & 804 (52.48) \\
\hline Uninsured & 341 (52.87) & $1354(49.22)$ & $704(45.95)$ & $1320(45.55)$ & $728(47.52)$ \\
\hline Observations & 645 & 2751 & 1532 & 2898 & 1532 \\
\hline
\end{tabular}

Notes: RM refers to Ringgit Malaysia. The entries refer to frequencies. Percentages in parentheses.

formed: Malay, Chinese, Indian and Others. Malay is the ethnic majority, followed by Chinese, Indian and Others. The possible answers for the question about marital status are single, married, widowed and divorced. Because of the small number of observations for widowed and divorced, these two categories are combined to form a single category.

Following the guideline of Mok et al. (2011), household size is grouped into three categories: small $(\leq 4)$, medium (5-7) and large $(\geq 8)$. In terms of employment status, the respondents are asked 'Are you currently working?' They respond with either 'yes' or 'no'. For those who respond 'yes' are considered to be employed. In addition to sociodemographic variables, the respondents are asked: 'Are you currently covered by health insurance?' If they answer 'yes', they are considered to have health insurance. Health insurance refers to any insurance company that pays for medical care costs if an individual gets sick or injured. The types of health insurance include both employersponsored insurance and private insurance. Since health insurance could affect disease preventive behaviours, such as use of health screening (Cheah, 2018), it would be interesting to identify whether it has an impact on physical activity.

\subsection{Statistical analysis}

The summary statistics of all the independent variables are calculated for each bodyweight category. Both bivariate and multivariate analyses are conducted. In terms of bivariate analysis, the time spent in vigorous, moderate and total physical activity across bodyweight category are analysed. To examine the correlates of sociodemographic factors to physical activity across bodyweight group and draw ceteris paribus conclusions, multivariate analysis is performed. We run a multiple linear regression of the time spent in vigorous, moderate and total physical activity on sociodemographic factors using least square, and the estimates are interpreted as marginal effects. This regression is estimated for each bodyweight group. Although there could be a better statistical approach to estimate this regression, our main interest is not to identify the best statistical model but to examine the relationship between sociodemographic factors and physical activity. Nonetheless, in an effort to ensure that the estimates are efficient, two diagnostic tests are performed. First, we conduct the White test to detect the potential heteroskedasticity issue. Then, we calculate the variance inflation factor (VIF) of all the variables to identify whether there is a multicollinearity problem. If VIF is more than ten, then it can be concluded that multicollinearity is a problem (Wooldridge, 2013). The significant level of all the tests is based on $p<0.05$. All the analyses are performed using the Stata statistical software (StataCorp, 2013).

\section{Results}

The summary statistics of the independent variables for all the bodyweight categories are presented in Table 1. Among underweight, normal and overweight individuals, the majority aged $\leq 29$ years (23.37-54.88\%), whereas the majority of obese I and obese II individuals aged $40-49$ years (23.76-25.05\%). Individuals aged $\geq 60$ are 
Table 2

Time spent in vigorous, moderate and total physical activity, by bodyweight. Source: NHMS 2011

\begin{tabular}{llll}
\hline Bodyweight & Vigorous & Moderate & Total \\
\hline Underweight & 144.94 & 199.48 & 344.42 \\
& $(463.39)$ & $(454.23)$ & $(661.24)$ \\
Normal & 152.86 & 238.04 & 390.89 \\
& $(460.71)$ & $(467.92)$ & $(683.21)$ \\
Overweight & 157.04 & 263.61 & 420.66 \\
& $(470.82)$ & $(506.13)$ & $(725.71)$ \\
Obese I & 151.32 & 237.70 & 389.02 \\
& $(450.86)$ & $(446.00)$ & $(670.03)$ \\
Obese II & 98.77 & 243.91 & 342.68 \\
& $(307.86)$ & $(438.25)$ & $(546.39)$ \\
F-statistics & & $2.30^{*}$ & $3.33^{*}$ \\
\hline
\end{tabular}

Note: *p-value $<0.05$.

a Test of equality of mean. Value are in average minutes per week (min/wk). Standard deviations in parentheses.

the minority in normal (11.45\%), overweight $(13.64 \%)$, obese I $(12.87 \%)$ and obese II $(10.25 \%)$ categories. With regard to education and income, a large proportion of individuals who are in underweight, normal, overweight, obese I and obese II categories have secondarylevel education (44.78-51.47\%) and monthly income of $\leq$ RM999 (39.72-51.78\%). Among underweight and normal individuals, only a small proportion have primary-level education (20.78-24.97\%) and monthly income of $\geq \mathrm{RM} 4000$ (2.64-7.09\%). Women are the majority in underweight $(52.40 \%)$, normal $(54.13 \%)$, overweight $(51.37 \%)$ and obese II $(60.90 \%)$ categories, whereas men are the majority in obese I category (51.04\%). Around half of the respondents in all the bodyweight groups are Malays (46.02-61.55\%). Only a small proportion of the respondents in underweight $(9.77 \%)$, normal $(9.16 \%)$, overweight $(9.60 \%)$ and obese I $(10.57 \%)$ categories are Indians. More than half of the respondents who are in normal, overweight, obese I and obese II categories are married (59.36-77.05\%), followed by those who are single (15.91-34.10\%) and divorced/widowed (6.54-8.36\%). The majority of the families in all the bodyweight groups are small (53.33-56.72\%), followed by medium (35.19-36.99\%) and large (6.85-9.92\%). The majority of the total respondents are employed (62.27-66.94\%). A large proportion of all the bodyweight groups of individuals are covered by insurance (50.78-54.45\%), except those who are underweight (47.13\%).

Bodyweight categorical differences in the time spent in vigorous, moderate and total physical activity are presented in Table 2. Overweight individuals spend $157.04 \mathrm{~min} / \mathrm{wk}$ in vigorous physical activity, followed by normal (152.86 min/wk), obese I (151.32 min/wk), underweight (144.94 min/wk) and obese II ( $98.77 \mathrm{~min} / \mathrm{wk})$. In terms of moderate physical activity, overweight individuals allocate the most time for it (263.61 min/wk), whilst obese II, normal, obese I and underweight individuals spend only $243.91 \mathrm{~min} / \mathrm{wk}, 238.04 \mathrm{~min} / \mathrm{wk}$, $237.70 \mathrm{~min} / \mathrm{wk}$ and $199.48 \mathrm{~min} / \mathrm{wk}$, respectively. Overall, overweight individuals spend around $420.66 \mathrm{~min} / \mathrm{wk}$ in total physical activity, compared with only $390.89 \mathrm{~min} / \mathrm{wk}, 389.02 \mathrm{~min} / \mathrm{wk}, 344.42 \mathrm{~min} / \mathrm{wk}$ and $342.68 \mathrm{~min} /$ wk spent by normal, obese I, underweight and obese II individuals, respectively.

Correlates of sociodemographic factors to vigorous physical activity, by bodyweight are illustrated in Table 3 . The constant in all the regressions is insignificant, indicating that the models do not have omitted variables. Also, the maximum VIFs are very small, and this implies that none of the models have a multicollinearity problem. It appears that the regressions for normal weight, overweight and obese I categories have heteroskedasticity issue as the value of White test is highly significant. Hence, robust standard errors are calculated for these regressions.

In underweight and normal categories, individuals aged $\geq 60$ years spend 110-184 min/wk less in vigorous physical activity than their counterparts aged $\leq 29$ years. Considering the effects of education, underweight, normal and obese I individuals with tertiary-level education spend $145 \mathrm{~min} / \mathrm{wk}, 99 \mathrm{~min} / \mathrm{wk}$ and $83 \mathrm{~min} /$ wk less in vigorous physical activity, respectively, compared with their peers who have only primary-level education. Among obese II individuals, having income of RM3000-3999 and $\geq$ RM4000, instead of $\leq$ RM999 reduces the time spent in vigorous physical activity by $84 \mathrm{~min} /$ wk and $102 \mathrm{~min} / \mathrm{wk}$, respectively. In all the bodyweight groups, males spend around 121-216 min/wk more in vigorous physical activity than females. Compared with Malays who have normal bodyweight, Indians with similar bodyweight category spend approximately $71 \mathrm{~min} / \mathrm{wk}$ less in vigorous physical activity, while Others spend about $97 \mathrm{~min} /$ wk more in vigorous physical activity. Having a large family size is positively associated with the time spent in vigorous physical activity in obese I category (69 $\mathrm{min} / \mathrm{wk}$ ).

Correlates of sociodemographic factors to moderate physical activity, by bodyweight are shown in Table 4. All the regressions have an insignificant constant and a low maximum VIF, thus omitted variable and multicollinearity are not a concern. Robust standard errors are calculated for the regression for normal weight category because the model does not have homoskedasticity.

In the groups of normal and obese I bodyweights, individuals aged 40-49 years spend about 71-78 min/wk more in moderate physical activity than individuals aged $\leq 29$ years. Among obese II individuals, having age of $\geq 60$ years instead of $\leq 29$ years, the time spent in moderate physical activity reduces by $112 \mathrm{~min} /$ wk. Underweight individuals with secondary-level education spend $114 \mathrm{~min} /$ wk more in moderate physical activity than their counterparts having only primarylevel education, whereas obese I individuals with tertiary-level education spend $59 \mathrm{~min} / \mathrm{wk}$ less in moderate physical activity than their primary-educated peers. In normal weight group, individuals having income of RM1000-1999, RM3000-3999 and $\geq$ RM4000 spend $62 \mathrm{~min} /$ wk, $89 \mathrm{~min} / \mathrm{wk}$ and $96 \mathrm{~min} / \mathrm{wk}$ less in moderate physical activity than those having income of $\leq \mathrm{RM} 999$. In overweight group, individuals who have income of RM1000-1999, RM2000-2999 and $\geq$ RM4000 allocate $102 \mathrm{~min} / \mathrm{wk}, 92 \mathrm{~min} / \mathrm{wk}$ and $200 \mathrm{~min} /$ wk less for moderate physical activity compared with individuals who have income of $\leq$ RM999. Among obese I individuals, having income of RM3000-3999 and $\geq \mathrm{RM} 4000$ instead of $\leq \mathrm{RM} 999$ is associated with reduced time spent (88-116 min/wk) in moderate physical activity. Obese I and II males spend $73 \mathrm{~min} /$ wk and $44 \mathrm{~min} /$ wk less in moderate physical activity, respectively, than their female counterparts. In the groups of normal, overweight and obese I bodyweights, Indians and Others spend about 72-139 min/wk and 101-129 min/wk less in moderate physical activity, respectively, than Malays. Underweight and obese II individuals with married marital status spend $97 \mathrm{~min} /$ wk and $104 \mathrm{~min} /$ wk more in moderate physical activity, respectively, than their single counterparts. Among all the bodyweight categories, being employed is positively associated with the time spent in moderate physical activity (61-137 $\mathrm{min} / \mathrm{wk})$.

Correlates of sociodemographic factors to total physical activity, by bodyweight are presented in Table 5 . Similar to the models related to vigorous and moderate physical activity, omitted variable and multicollinearity are not a problem. However, heteroskedasticity is detected in the regressions for normal weight and obese I categories. Therefore, robust standard errors are calculated for these regressions.

Among normal and obese II individuals, those aged $\geq 60$ years spend 146-155 min/wk less in total physical activity than those aged $\leq 29$ years. Normal weight individuals with secondary- and tertiary-level education spend $91 \mathrm{~min} / \mathrm{wk}$ and $155 \mathrm{~min} /$ wk less in total physical activity, respectively, compared with their counterparts with primarylevel education. Obese I individuals with tertiary-level education spend $141 \mathrm{~min} /$ wk less in total physical activity than their peers with primarylevel education. In overweight category, individuals having income of RM1000-1999 and $\geq$ RM4000 spend $142 \mathrm{~min} /$ wk and $296 \mathrm{~min} /$ wk less in total physical activity, respectively, than their counterparts who have 
Table 3

Correlates of sociodemographic factors to vigorous physical activity, by bodyweight. Source: NHMS 2011

\begin{tabular}{|c|c|c|c|c|c|}
\hline Variables & Underweight & Normal & Overweight & Obese I & Obese II \\
\hline Constant & $554(2572)$ & -53 (2379) & $-17039(21604)$ & 719 (3481) & 89 (336) \\
\hline BMI & $-63(312)$ & 17 (228) & $1457(1800)$ & $-46(255)$ & $-1(17)$ \\
\hline $\mathrm{BMI}^{2}$ & $2(9)$ & $-1(5)$ & $-31(37)$ & $1(5)$ & $1(1)$ \\
\hline \multicolumn{6}{|l|}{ Age (years) } \\
\hline 29 & - & - & - & - & - \\
\hline $30-39$ & $-80(60)$ & $-29(29)$ & $43(43)$ & $9(35)$ & $42(28)$ \\
\hline $40-49$ & $-118(72)$ & $2(33)$ & $49(41)$ & $1(39)$ & 51 (29) \\
\hline $50-59$ & $-88(80)$ & $-33(36)$ & $-4(42)$ & $-16(38)$ & $18(31)$ \\
\hline$\geq 60$ & $-184(83)^{*}$ & $-110(40)^{*}$ & $-63(45)$ & $-69(37)$ & $-34(39)$ \\
\hline \multicolumn{6}{|l|}{ Education } \\
\hline Primary & - & - & - & - & - \\
\hline Secondary & $-74(57)$ & $-70(32)^{*}$ & $-45(38)$ & $-31(28)$ & $-10(22)$ \\
\hline Tertiary & $-145(70)^{*}$ & $-99(36)^{*}$ & $-65(45)$ & $-83(33)^{*}$ & $-36(29)$ \\
\hline \multicolumn{6}{|l|}{ Income (RM) } \\
\hline$\leq 999$ & - & - & - & - & - \\
\hline 1000-1999 & $-55(49)$ & $40(26)$ & $-39(35)$ & $35(28)$ & $-26(21)$ \\
\hline 2000-2999 & $-61(68)$ & $30(36)$ & $30(52)$ & $-38(30)$ & $-30(28)$ \\
\hline $3000-3999$ & $-132(90)$ & $36(38)$ & $-78(48)$ & $-52(35)$ & $-84(36)^{*}$ \\
\hline$\geq 4000$ & $-169(123)$ & $-19(46)$ & $-96(55)$ & $-46(37)$ & $-102(35)^{*}$ \\
\hline \multicolumn{6}{|l|}{ Gender } \\
\hline Male & 191 (39)* & $193(17)^{*}$ & $216(25)^{*}$ & $151(18)^{*}$ & $121(18)^{*}$ \\
\hline Female & - & - & - & - & - \\
\hline \multicolumn{6}{|l|}{ Ethnicity } \\
\hline Malay & - & - & - & - & - \\
\hline Chinese & $28(44)$ & $-26(17)$ & $10(28)$ & -17 (19) & $24(23)$ \\
\hline Indian & $-33(62)$ & $-71(18)^{*}$ & $16(41)$ & $27(32)$ & $-37(24)$ \\
\hline Others & $-112(61)$ & $97(35)^{*}$ & $4(41)$ & $22(34)$ & $29(27)$ \\
\hline \multicolumn{6}{|l|}{ Marital status } \\
\hline Single & - & - & - & - & - \\
\hline Married & $5(48)$ & $33(24)$ & $-51(38)$ & $-26(36)$ & $-21(27)$ \\
\hline Divorce & 22 (95) & $28(32)$ & $-61(40)$ & $-57(40)$ & $19(41)$ \\
\hline \multicolumn{6}{|l|}{ Family size } \\
\hline Small & - & - & - & - & - \\
\hline Medium & 71 (39) & $16(18)$ & $-11(25)$ & $22(18)$ & $1(17)$ \\
\hline Large & $-43(62)$ & $76(46)$ & $77(66)$ & $69(42)^{*}$ & $-19(31)$ \\
\hline \multicolumn{6}{|l|}{ Employment } \\
\hline Employed & $137(47)^{*}$ & $67(19)^{*}$ & $65(28)^{*}$ & $87(19)^{*}$ & $61(21)^{*}$ \\
\hline Unemployed & - & - & - & - & - \\
\hline \multicolumn{6}{|l|}{ Insurance } \\
\hline Insured & $4(40)$ & -37 (19) & $-37(26)$ & $-28(20)$ & $8(17)$ \\
\hline Uninsured & - & - & - & - & - \\
\hline White test & 194.35 & 379.35 & 307.16 & 350.46 & 225.94 \\
\hline$p$-value & 0.948 & $<0.001$ & $<0.001$ & $<0.001$ & 0.635 \\
\hline Max. VIF & 3.18 & 2.62 & 2.57 & 2.68 & 2.79 \\
\hline Observations & 645 & 2751 & 1532 & 2898 & 1532 \\
\hline
\end{tabular}

Notes: BMI refers to body mass index. RM refers to Ringgit Malaysia. VIF refers to variance inflation factor. ${ }^{*} p$-value $<0.05$. Standard errors in parentheses.

income of $\leq$ RM999. Among obese I and obese II individuals, having income of RM 3000-3999 and $\geq$ RM4000 instead of $\leq$ RM999 reduces the time spent in total physical activity by $142-168 \mathrm{~min} / \mathrm{wk}$ and 134-148 $\mathrm{min} / \mathrm{wk}$, respectively. Of all the bodyweight categories, males spend $77-218 \mathrm{~min} /$ wk more in total physical activity than females. In terms of ethnicity, Indians in overweight and obese I categories spend $155 \mathrm{~min} /$ wk and $100 \mathrm{~min} /$ wk more in total physical activity, respectively, than Malays. Moreover, Others in normal, overweight and obese I categories allocate $225 \mathrm{~min} / \mathrm{wk}, 133 \mathrm{~min} /$ wk and $123 \mathrm{~min} /$ wk more for total physical activity, respectively, compared with Malays. Being employed increases the time spent in total physical activity by 87-178 $\mathrm{min} / \mathrm{wk}$ in all the bodyweight groups.

\section{Discussion}

In the present study, factors associated with participation in physical activity among different bodyweight groups of adults are wellidentified. Our main interest is to seek a better understanding of sociodemographic differences in vigorous and moderate physical activity among overweight and obese adults given that physical activity plays a very important role in reducing the risk of developing various diseases caused by excessive accumulation of fat in the body. Results of bivariate analysis show that of all the bodyweight groups, overweight individuals spend the most time in vigorous, moderate and total physical activity, while obese II individuals allocate the least time for moderate vigorous and total physical activity. These findings have two implications. First, overweight individuals are more concerned about their body image compared with their lean counterparts, and consequently are more inclined to participate in physical activity (Reel et al., 2007). Second, obese II individuals tend to find difficulty in performing physical activity, thus they are unlikely to make an effort to exercise. As pointed out by Brock et al. (2010), heavy bodyweight may pose as a barrier that prevents individuals from engaging in physical activity. In terms of multivariate analysis, age, education, income, gender, ethnicity, marital status, family size and employment status are found to be significantly associated with participation in physical activity among overweight, obese I and obese II individuals. Since bivariate analysis does not provide any insight into the relationship between physical activity and sociodemographic factors, we turn our discussions to multivariate analysis and compare our results between Malaysia and developed countries.

While age is not significantly associated with physical activity 
Table 4

Correlates of sociodemographic factors to moderate physical activity, by bodyweight. Source: NHMS 2011

\begin{tabular}{|c|c|c|c|c|c|}
\hline Variables & Underweight & Normal & Overweight & Obese I & Obese II \\
\hline Constant & $-3281(2601)$ & $-3140(2574)$ & 20816 (24902) & $-293(3372)$ & 527 (488) \\
\hline BMI & 411 (315) & 312 (247) & -1735 (2077) & 39 (247) & $-12(25)$ \\
\hline $\mathrm{BMI}^{2}$ & $-13(10)$ & $-7(6)$ & $36(43)$ & $-1(4)$ & $1(1)$ \\
\hline \multicolumn{6}{|l|}{ Age (years) } \\
\hline 29 & - & - & - & - & - \\
\hline $30-39$ & $-55(60)$ & $41(32)$ & $11(44)$ & 47 (30) & $-64(41)$ \\
\hline $40-49$ & $-63(73)$ & $71(36)^{*}$ & $56(47)$ & $78(31)^{*}$ & $-39(43)$ \\
\hline $50-59$ & $28(81)$ & $53(40)$ & $73(50)$ & $35(32)$ & $-27(45)$ \\
\hline$\geq 60$ & $11(84)$ & $-45(43)$ & $-70(60)$ & $2(39)$ & $-112(57)^{*}$ \\
\hline \multicolumn{6}{|l|}{ Education } \\
\hline Primary & - & - & - & - & - \\
\hline Secondary & $114(58)^{*}$ & $-21(30)$ & $-11(36)$ & $-8(23)$ & $3(32)$ \\
\hline Tertiary & $94(70)$ & $-56(34)$ & $-39(45)$ & $-59(30)^{*}$ & $3(43)$ \\
\hline \multicolumn{6}{|l|}{ Income (RM) } \\
\hline$\leq 999$ & - & - & - & - & - \\
\hline 1000-1999 & $-39(49)$ & $-62(26)^{*}$ & $-102(36)^{*}$ & $-14(24)$ & $-2(31)$ \\
\hline 2000-2999 & $103(69)$ & $-40(37)$ & $-92(44)^{*}$ & $-54(29)$ & $-37(41)$ \\
\hline 3000-3999 & $-74(91)$ & $-89(40)^{*}$ & $-74(59)$ & $-116(35)^{*}$ & $-58(52)$ \\
\hline$\geq 4000$ & $-70(124)$ & $-96(40)^{*}$ & $-200(55)^{*}$ & $-88(36)^{*}$ & $-47(51)$ \\
\hline \multicolumn{6}{|l|}{ Gender } \\
\hline Male & -27 (39) & $-2(18)$ & -17 (29) & $-73(18)^{*}$ & $-44(26)^{*}$ \\
\hline Female & - & - & - & - & - \\
\hline \multicolumn{6}{|l|}{ Ethnicity } \\
\hline Malay & - & - & - & - & - \\
\hline Chinese & $42(45)$ & $33(20)$ & $23(32)$ & $25(21)$ & $1(34)$ \\
\hline Indian & $12(63)$ & $78(36)^{*}$ & $139(46)^{*}$ & $72(28)^{*}$ & $16(35)$ \\
\hline Others & $235(61)^{*}$ & $127(31)^{*}$ & $129(43)^{*}$ & $101(27)^{*}$ & 33 (39) \\
\hline \multicolumn{6}{|l|}{ Marital status } \\
\hline Single & - & - & - & - & - \\
\hline Married & $97(49)^{*}$ & 14 (29) & $20(41)$ & $-4(29)$ & $104(39)^{*}$ \\
\hline Divorce & $8(96)$ & 14 (49) & $-32(70)$ & $20(44)$ & 64 (59) \\
\hline \multicolumn{6}{|l|}{ Family size } \\
\hline Small & - & - & - & - & - \\
\hline Medium & $1(39)$ & $17(20)$ & $22(28)$ & 11 (18) & $-2(24)$ \\
\hline Large & $21(63)$ & $-21(34)$ & $13(52)$ & $-15(32)$ & $-1(44)$ \\
\hline \multicolumn{6}{|l|}{ Employment } \\
\hline Employed & $36(48)$ & $69(23)^{*}$ & $59(35)^{*}$ & $90(23)^{*}$ & $26(30)$ \\
\hline Unemployed & - & - & - & - & - \\
\hline \multicolumn{6}{|l|}{ Insurance } \\
\hline Insured & $-69(40)$ & $6(21)$ & 55 (29) & $-15(18)$ & $-14(25)$ \\
\hline Uninsured & - & - & - & - & - \\
\hline White test & 175.42 & 298.71 & 216.95 & 259.21 & 170.75 \\
\hline$p$-value & 0.996 & 0.004 & 0.808 & 0.143 & 0.999 \\
\hline Max. VIF & 3.18 & 2.62 & 2.57 & 2.68 & 2.79 \\
\hline Observations & 645 & 2751 & 1532 & 2898 & 1532 \\
\hline
\end{tabular}

Notes: BMI refers to body mass index. RM refers to Ringgit Malaysia. VIF refers to variance inflation factor. ${ }^{*} p$-value $<0.05$. Standard errors in parentheses.

participation among overweight adults, it has a positive influence on moderate physical activity among obese I adults and a negative impact on moderate and total physical activity among individuals who are obese II. However, these age-physical activity relationships are not strong because only a few estimates are statistically significant. Nevertheless, they are important for policy makers who want to promote physically active lifestyle among obese people. An implication of our findings is that older obese II adults may face greater barriers to engagement in physical activity than their younger counterparts, even though they may be more aware of their health. The majority of previous studies that have not considered bodyweight groups have found a negative relationship between age and physical activity. Farrell and Shields (2002) and Downward and Rasciute (2010) have found that older individuals are less likely to participate in physical activity than younger individuals and also spend less time. Although these researchers have used different datasets of England (Health Survey of England vs DCMS Taking Part Survey) and statistical models (probit vs tobit), they have reached the same conclusion. Similar findings have been evidenced in Scotland (Eberth and Smith, 2010), the US (Humphreys and Ruseski, 2011), as well as in Malaysia (Cheah and Poh, 2014; Cheah et al., 2017).
Education is only significant in explaining participation in physical activity among obese I individuals. In particular, well-educated obese I individuals spend less time in vigorous, moderate and total physical activity than their less-educated counterparts. However, physical activity behaviours among overweight and obese II adults do not seem to be influenced by education. Past Malaysian studies that did not consider bodyweight and intensity of physical activity also found a negative relationship between education and physical activity participation (Cheah and Poh, 2014; Cheah et al., 2017). However, previous studies using German data have suggested otherwise that education is positively associated with participation in physical activity (Lechner, 2009; Ruseski et al., 2011). Despite using different statistical methods, Farrell and Shields (2002), Downward and Rasciute (2010) and Eberth and Smith (2010), who have based their studies on samples of the UK, have also concluded that well-educated individuals are more likely to engage in physical activity than less-educated individuals. In the US and Australia, Humphreys and Ruseski (2011) and Brown and Roberts (2011) have suggested that education is associated with an increased likelihood of participating in physical activity. Our finding on education can be explained by the following reason. Since the majority of welleducated individuals work in white collar jobs, they are less physically 
Table 5

Correlates of sociodemographic factors to total physical activity, by bodyweight. Source: NHMS 2011

\begin{tabular}{|c|c|c|c|c|c|}
\hline Variables & Underweight & Normal & Overweight & Obese I & Obese II \\
\hline Constant & $-2727(3721)$ & $-3193(3649)$ & 3777 (35342) & $426(5343)$ & 617 (606) \\
\hline BMI & 347 (451) & 328 (349) & $-278(2948)$ & -7 (389) & $-14(32)$ \\
\hline $\mathrm{BMI}^{2}$ & $-10(14)$ & $-8(8)$ & $6(61)$ & $1(7)$ & $1(1)$ \\
\hline \multicolumn{6}{|l|}{ Age (years) } \\
\hline 29 & - & - & - & - & - \\
\hline $30-39$ & $-135(86)$ & $12(45)$ & $53(63)$ & $56(50)$ & $-22(51)$ \\
\hline $40-49$ & $-181(104)$ & $73(50)$ & 105 (67) & $78(55)$ & $12(53)$ \\
\hline $50-59$ & $-59(116)$ & $20(55)$ & $69(71)$ & 19 (53) & $-9(56)$ \\
\hline$\geq 60$ & $-173(120)$ & $-155(59)^{*}$ & $-133(85)$ & $-66(55)$ & $-146(71)^{*}$ \\
\hline \multicolumn{6}{|l|}{ Education } \\
\hline Primary & - & - & - & - & - \\
\hline Secondary & $40(83)$ & $-91(44)^{*}$ & $-56(51)$ & -39 (39) & $-7(40)$ \\
\hline Tertiary & $-51(101)$ & $-155(51)^{*}$ & $-104(63)$ & $-141(44)^{*}$ & $-33(53)$ \\
\hline \multicolumn{6}{|l|}{ Income (RM) } \\
\hline$\leq 999$ & - & - & - & - & - \\
\hline 1000-1999 & $-94(71)$ & $-22(37)$ & $-142(51)^{*}$ & $21(43)$ & $-28(39)$ \\
\hline 2000-2999 & $43(99)$ & $-10(51)$ & $-61(63)$ & $-92(44)^{*}$ & $-66(51)$ \\
\hline 3000-3999 & $-206(131)$ & $-53(61)$ & $-152(84)$ & $-168(49)^{*}$ & $-142(64)^{*}$ \\
\hline$\geq 4000$ & $-239(178)$ & $-115(63)$ & $-296(78)^{*}$ & $-134(53)^{*}$ & $-148(63)^{*}$ \\
\hline \multicolumn{6}{|l|}{ Gender } \\
\hline Male & $218(56)^{*}$ & $191(26)^{*}$ & $198(41)^{*}$ & $79(27)^{*}$ & $77(32)^{*}$ \\
\hline Female & - & - & - & - & - \\
\hline \multicolumn{6}{|l|}{ Ethnicity } \\
\hline Malay & - & - & - & - & - \\
\hline Chinese & $70(64)$ & 7 (27) & $34(45)$ & $8(28)$ & $25(42)$ \\
\hline Indian & $-22(90)$ & $7(41)$ & $155(65)^{*}$ & $100(51)^{*}$ & $-21(44)$ \\
\hline Others & $123(88)$ & $225(48)^{*}$ & $133(61)^{*}$ & $123(50)^{*}$ & $63(48)$ \\
\hline \multicolumn{6}{|l|}{ Marital status } \\
\hline Single & - & - & - & - & - \\
\hline Married & $101(70)$ & 47 (39) & -31 (59) & $-31(53)$ & 84 (49) \\
\hline Divorce & 29 (137) & $42(58)$ & -93 (99) & $-37(68)$ & $83(74)$ \\
\hline \multicolumn{6}{|l|}{ Family size } \\
\hline Small & - & - & - & - & - \\
\hline Medium & $73(56)$ & $34(28)$ & 11 (39) & $32(26)$ & $-1(30)$ \\
\hline Large & $-22(90)$ & $55(57)$ & $90(74)$ & $54(54)$ & $-20(55)$ \\
\hline \multicolumn{6}{|l|}{ Employment } \\
\hline Employed & $173(68)^{*}$ & $136(31)^{*}$ & 124 (49)* & $178(33)^{*}$ & $87(37)^{*}$ \\
\hline Unemployed & - & - & - & - & - \\
\hline \multicolumn{6}{|l|}{ Insurance } \\
\hline Insured & $-65(57)$ & $-31(29)$ & $18(41)$ & $-43(28)$ & $-6(32)$ \\
\hline Uninsured & - & - & - & - & - \\
\hline White test & 188.81 & 315.94 & 259.40 & 352.27 & 202.50 \\
\hline$p$-value & 0.973 & $<0.001$ & 0.142 & $<0.001$ & 0.933 \\
\hline Max. VIF & 3.18 & 2.62 & 2.57 & 2.68 & 2.79 \\
\hline Observations & 645 & 2751 & 1532 & 2898 & 1532 \\
\hline
\end{tabular}

Notes: BMI refers to body mass index. RM refers to Ringgit Malaysia. VIF refers to variance inflation factor. * $p$-value $<0.05$. Standard errors in parentheses.

active in general compared with their less-educated peers (Humphreys and Ruseski, 2015). Therefore, we are able to conclude that a policy that focuses primarily on improving education level among overweight and obese II individuals may not yield the desired objective because education cannot alter these individuals' physical activity behaviours. In other words, even though overweight and obese II people are welleducated, they may not spend adequate time in any intensity level of physical activity.

Higher income obese II individuals spend less time in vigorous physical activity than their lower income counterparts, while higher income overweight and obese I individuals allocate less time for moderate physical activity than those who have lower income. Also, individuals in these bodyweight groups reduce their time for total physical activity when their income increases. This income-physical activity relationship has been shared by Cheah and Poh (2014) and Cheah et al. (2017), but it contradicts the findings evidenced in developed countries. Based on the Australian data, findings of Maruyama and Yin (2012) correspond to those of Brown and Roberts (2011) that higher income earners are more likely to engage in physical activity than lower income earners and also exercise more. In the US, Meltzer and Jena (2010) and Humphreys and Ruseski (2011) using least squares and the Cragg model, respectively, found that income is positively associated with participation in physical activity. These findings have also been evidenced by Farrell and Shields (2002) and Downward and Rasciute (2015), who have drawn on the data of the UK. The reason highlighted by Farrell and Shields (2002) is that individuals need money to purchase exercise equipment. However, in Malaysia, income may not pose as a serious barrier to physical activity participation as public exercise programmes are quite easily accessible. A plausible reason for our findings on income may be attributable to opportunity costs. In general, higher income individuals tend to face higher opportunity costs of time than lower income individuals because they earn higher wages (Cheah and Poh, 2014; Cheah et al., 2017). As such, they are likely to find physical activity less attractive than works. A better understanding of the relationship between opportunity costs and physical activity should be supplemented by future studies that can incorporate wage as a covariate. Nonetheless, an important implication of our findings is that in order to promote physically active lifestyle among overweight and obese adults, high income earners should be the main focus rather than low income earners.

Overweight, obese I and obese II males seem to spend more time in vigorous and total physical activity than their female counterparts, but 
they allocate less time for moderate physical activity. Perhaps, this is due to the fact that males are more likely to participate in sports, which require more energy, while females are more likely to participate in less strenuous activities, such as household activities (Humphreys and Ruseski, 2011). Another plausible reason is that females are likely to avoid participating in vigorous activities that may result in masculine appearance (Cheah et al., 2016). Surprisingly, however, gender is not able to determine participation in moderate physical activity among overweight individuals. Examining sociodemographic differences in intensity of physical activity among various bodyweight groups indicates that the relationship between physical activity and gender is not as straightforward as it seemed. Most of the previous studies have consistently found that males are more likely to participate in physical activity than females, but they have not examined gender differences in intensity of physical activity across bodyweight group (Farrell and Shields, 2002; Downward and Riordan, 2007; Downward, 2007; Humphreys and Ruseski, 2007; Downward and Rasciute, 2015). Similarly too with the Malaysian studies (Cheah and Poh, 2014; Cheah et al., 2017). Hence, an inappropriate conclusion may be generated and consequently, less optimal policies are recommended. For instance, nationwide policies that are aimed at promoting participation in moderate physical activity among females instead of males, especially those who are obese are unlikely to yield promising outcomes. Instead, we suggest policy makers to focus on encouraging overweight and obese women to spend more time in vigorous physical activity in order to increase their overall level of physical activity.

Somewhat consistent with the findings of Cheah and Poh (2014) and Cheah et al. (2017), employed individuals in all the bodyweight categories tend to spend more time in vigorous, moderate and total physical activity than their unemployed counterparts. These findings are, however, in contrast to evidences of Farrell and Shields (2002) and Downward and Riordan (2007), which show a negative relationship between being employed and physical activity participation. These researchers have claimed that employed individuals have less time on their hand than unemployed individuals and consequently are less able to spend time in physical activity. Because physical activity measured in our study include work related activities, employed individuals are generally more physically active than those who are unemployed. While a variety of potential social issues may be at play, analysing the social setting of Malaysia is beyond the scope of the present study. Based on our findings, we are able to conclude that although employed individuals are less likely to spend time in physical activity during their leisure than unemployed individuals, they are more physically active in general. It appears that if studies do not take into account work related physical activity and instead conclude that employed individuals are less physically active than unemployed individuals, this may have dire consequences for policy. Our findings, therefore, suggest that policy makers should focus more on unemployed individuals than employed individuals, if the objective of reducing the prevalence of physical inactivity among overweight and obese adults is to be met. If data is available, future studies may want to categorise physical activity into work, leisure and travel for a more in-depth analysis and investigation.

Among overweight and obese I individuals, Indians and Others are likely to spend more time in moderate and total physical activity than Malays. Somewhat similar findings have been evidenced by Cheah et al. (2017). In particular, Cheah et al. (2017) have found that Malays are less likely to participate in physical activity than Indians and also spend less time. The reason for these ethnic differences in physical activity may be attributable to cultural, religious and ethnic privilege factors. Due to secondary data being used in our study, we are unable to identify the exact reasons. A comprehensive qualitative research is, therefore, suggested to be conducted in order to acquire a better understanding of the factors explaining the relationship between ethnicity and physical activity. Nonetheless, our findings imply that policy makers should give attention to overweight and obese I adults who are from Malay ethnic group.
Marital status and family size are among the least important sociodemographic variables. This is because their effects on physical activity among overweight and obese individuals are not very significant. For instance, marital status only has a significant effect on moderate physical activity among obese II adults, while family size is only significantly associated with vigorous physical activity among obese I adults. Although married obese II individuals spend more time in moderate physical activity than their single counterparts, they do not spend more time in vigorous and total physical activity. Similarly, obese I adults having a large family size spend more time in vigorous physical activity than their counterparts who have a small family size, but they do not spend more time in moderate and total physical activity. In addition, our findings show that insurance is not significantly associated with physical activity, which does not support our hypothesis.

Our study has several limitations. First, because the data used in our study is a cross-sectional data instead of longitudinal, our results cannot be interpreted as causal relationships. Second, information on wage is unavailable, thus the substitution and income effects on physical activity cannot be well-identified. Third, given that all the information is self-reported, reporting error may occur. Fourth, owing to the data limitation, issue of built environment and natural opportunities to get exercise are not considered in our analysis. Despite these limitations, the present study as to our knowledge is the first to shed light on sociodemographic factors associated with participation in vigorous and moderate physical activity among overweight and obese adults, using data of a rapidly growing developing country.

\section{Conclusion}

In view of the importance of physical activity in preventing various diseases, the present study examines sociodemographic factors associated with participation in physical activity among people who are overweight and obese. We stratify our analyses by bodyweight group and take into consideration the intensity of physical activity. Our findings show that higher income overweight and obese individuals tend to spend less time in all intensity levels of physical activity as compared to their lower income counterparts. Furthermore, although obese males spend less time in moderate physical activity than obese females, they spend more time in vigorous and total physical activity. Moreover, being employed is positively correlated with the time spent in all intensity levels of physical activity among overweight and obese individuals. Additionally, education is only significant in determining physical activity participation among obese I individuals as having tertiary-level education is associated with reduced time spent in both vigorous and moderate physical activity. Based on these results, policy makers should be able to formulate more effective intervention measures directed toward promoting physically active lifestyle among overweight and obese people and consequently, an improvement in public health.

\section{Conflict of interest}

The authors have no competing interests to declare.

\section{Acknowledgements}

The authors would like to thank the Director General of Health, Malaysia for his permission to use the data from the National Health and Morbidity Survey 2011 and to publish this paper. This research received funding from the Fundamental Research Grant Scheme (FRGS) (KOD SO 14218), which is sponsored by the Ministry of Education Malaysia. 


\section{References}

Ainsworth, B.E., Haskell, W.L., Leon, A.S., Jacobs, D.R., Montoye, H.J., Sallis, J.F, Paffenbarger, R.S., 1993. Compendium of physical activities: classification of energy costs of human physical activities. Med. Sci. Sport. Exerc. 25 (1), 71-80.

Brock, D.W., Chandler-Laney, P.C., Alvarez, J.A., Gower, B.A., Gaesser, G.A., Hunter, G.R., 2010. Perception of exercise difficulty predicts weight regain in formerly overweight women. Obesity 18 (5), 982-986.

Brown, H., Roberts, J., 2011. Exercising choice: the economic determinants of physical activity behaviour of an employed population. Soc. Sci. Med. 73 (3), 383-390.

Chan, Y.Y., Lim, K.K., Lim, H.K., Teh, C.H., Kee, C.C., Cheong, S.M., Khoo, Y.Y., Baharudin, A., Ling, M.Y., Omar, M.A., Ahmad, N.A., 2017. Physical activity and overweight/obesity among Malaysian adults: findings from the 2015 National Health and morbidity survey (NHMS). BMC Public Health 17 (733).

Cheah, Y.K., 2018. The utilization of diagnostic tests among the elderly: evidence from Malaysia. Soc. Econ. Plan. Sci. 62, 121-128.

Cheah, Y.K., Azahadi, M., Phang, S.N., Hazilah, N., 2017. Factors affecting participation decision and amount of physical activity among urban dwellers in Malaysia. Public Health 146, 84-91.

Cheah, Y.K., Lim, H.K., Kee, C.C., Ghazali, S.M., 2016. Factors associated with participation in physical activity among adolescents in Malaysia. Int. J. Adolesc. Med. Health 28 (4), 419-427.

Cheah, Y.K., Poh, B.K., 2014. The determinants of participation in physical activity in Malaysia. Osong Public Health and Research Perspectives 5 (1), 20-27.

Downward, P., 2007. Exploring the economic choice to participate in sport: results from the 2002 general household survey. Int. Rev. Appl. Econ. 21 (5), 633-653.

Downward, P., Rasciute, S., 2015. Exploring the covariates of sport participation for health: an analysis of males and females in England. J. Sport. Sci. 33 (1), 67-76.

Downward, P., Rasciute, S., 2010. The relative demands for sports and leisure in England. Eur. Sport Manag. Q. 10 (2), 189-214.

Downward, P., Riordan, J., 2007. Social interactions and the demand for sport: an economic analysis. Contemp. Econ. Policy 25 (4), 518-537.

Eberth, B., Smith, M.D., 2010. Modelling the participation decision and duration of sporting activity in Scotland. Econ. Modell. 27 (4), 822-834.

Farrell, L., Shields, M.A., 2002. Investigating the economic and demographic determinants of sporting participation in England. J. R. Stat. Soc. 165 (2), 335-348.

Humphreys, B.R., Ruseski, J.E., 2011. An economic analysis of participation and time spent in physical activity. B. E. J. Econ. Anal. Policy 11 (1) Article 47.
Humphreys, B.R., Ruseski, J.E., 2007. Participation in physical activity and government spending on parks and recreation. Contemp. Econ. Policy 25 (4), 538-552.

Humphreys, B.R., Ruseski, J.E., 2015. The economic choice of participation and time spent in physical activity and sport in Canada. International Journal of Sport Finance 10 (2), 138-159.

Institute for Public Health, 2011. National Health and Morbidity Survey 2011. Ministry of Health Malaysia, Putrajaya.

Institute for Public Health, 2015. National Health and Morbidity Survey 2015: Noncommunicable Diseases, Risk Factors and Other Health Problems. Ministry of Health Malaysia, Putrajaya.

Lechner, M., 2009. Long-run labour market and health effects of individual sports activities. J. Health Econ. 28 (4), 839-854.

Lum, M., 2018. Malaysia Is Asia's Fattest Country. Retrieved. https://www.star2.com/ health/2018/08/14/fat-state-of-affairs/, Accessed date: 1 April 2019.

Maruyama, S., Yin, Q., 2012. The opportunity cost of exercise: do higher-earning Australians exercise longer, harder or both? Health Policy 106 (2), 187-194.

Meltzer, D.O., Jena, A.B., 2010. The economics of intense exercise. J. Health Econ. 29 (3), 347-352.

Mok, T.P., Maclean, G., Dalziel, P., 2011. Household size economies: Malaysian evidence. Econ. Anal. Policy 41 (2), 203-223.

Reel, J.J., Greenleaf, C., Baker, W.K., Aragon, S., Bishop, D., Cachaper, C., Handwerk, P., Locicero, J., Rathburn, L., Reid, W.K., Hattie, J., 2007. Relations of body concerns and exercise behavior: a meta-analysis. Psychol. Rep. 101 (3), 927-942.

Ruseski, J.E., Humphreys, B.R., Hallmann, K., Breuer, C., 2011. Family structure, time constraints, and sports participation. European Review of Aging and Physical Activity 8 (2), 57-66.

StataCorp, 2013. Stata Statistical Software: Release 13.1. Stata Corporation, College Station, TX.

Tan, A.K.G., Yen, S.T., Feisul, M.I., 2012. Determinants of body weight status in Malaysia: an ethnic comparison. Int. J. Public Health 57 (2), 279-288.

Wooldridge, J., 2013. Introductory Econometrics: A Modern Approach, fifth ed. SouthWestern Cengage Learning, Ohio.

World Health Organization, 2018a. Obesity and overweight. Retrieved. https://www. who.int/news-room/fact-sheets/detail/obesity-and-overweight, Accessed date: 1 April 2019

World Health Organization, 2018b. Physical activity. Retrieved. https://www.who.int/ news-room/fact-sheets/detail/physical-activity, Accessed date: 1 April 2019. 